\title{
Carbonation resistance of high volume fly ash concrete
}

\author{
REIS Rui ${ }^{1, a}$, MALHEIRO Raphaele ${ }^{1, b}$, CAMÕES Aires ${ }^{1, c}$ e RIBEIRO Manuel ${ }^{2, d}$ \\ ${ }^{1} \mathrm{C}-\mathrm{TAC}$, Department of Civil Engineering, University of Minho, Campus de Azurém, 4800-058, \\ Guimarães, Portugal \\ 2UIDM, ESTG, Polytechnic Institute of Viana do Castelo, 4900-347, Viana do Castelo, Portugal \\ aruicunhareis@gmail.com, braphamalheiro@gmail.com, caires@civil.uminho.pt, \\ dribeiro@estg.ipvc.pt
}

Keywords: Carbonation, Sustainability, Durability, Fly Ash.

\begin{abstract}
The cement industry is responsible for a large part of the global environmental problems: is the largest consumer of natural resources; the most responsible for the emission of greenhouse gases, including about $1.8 \mathrm{Gt}$ of $\mathrm{CO}_{2}$; and requires huge amounts of energy, corresponding to between 12 and $15 \%$ of industrial energy use. The cement is also not used in the most appropriate manner, since $40 \%$ of the consumption of concrete is due to the renovation and repair of buildings, making concrete structures inefficient because its durability is relatively low. However, in the future, concrete can and should evolve in order to improve its eco-efficiency, with a smaller amount of cement in its composition, replacing it with high quantities of mineral additions, particularly fly ash. Nevertheless, current technology may not allow this type of concrete to be very efficient, because its long-term durability may be compromised. In fact, with increasing dosage of pozzolanic mineral additions, alkali paste components are consumed in the reaction leaving it vulnerable to concrete carbonation which may compromise the passivation layer needed for steel rebar protection against corrosion. This article explores a promising approach to mitigate this problem, which consists in the careful addition of hydrated lime in the concrete composition, highlighting the synergy of its components, significantly enhancing its carbonation resistance. It is proposed, therefore, to manufacture a concrete with high volume of fly ash, low cement content and high service life period: an efficient and sustainable concrete. In this context, an experimental campaign was developed with the aim of characterization of pastes behavior with high fly ash content, in particular with respect to its durability. The results will be presented and properly analyzed.
\end{abstract}

\section{Introduction}

The corrosion of reinforcing steel embedded in concrete is one of the most serious forms of durability related problems, common in building structures [1-5]. Corrosion is the main vehicle for degradation of reinforced concrete structures and consequently negatively affects its lifetime [510]. Besides the damage caused to buildings, one must take into account and consider the additional economic costs of rehabilitation, and social and operational losses. If corrosion is not detected and treated, the concrete will be more exposed to aggressive agents, providing the appearance of more damage with consequent cyclic deterioration. In this circumstances its performance may be drastically reduced and, consequently, also its service lifetime [7]. Carbonation is precisely one of the most important sources of corrosion occurring in reinforcement steel of concrete structures [3,5]. In a simplified form, that carbonation is a case of chemical attack in which the aggressive agents are the constituents of atmosphere gases, primarily carbon dioxide $\left(\mathrm{CO}_{2}\right)$, sulfur dioxide $\left(\mathrm{SO}_{2}\right)$ and hydrogen sulfide $\left(\mathrm{H}_{2} \mathrm{~S}\right)$ [5, 11, 12] . These, usually diffuse in gaseous form into the pore solution of porous system, the cracks occurrence in the interfacial transition zone between cement paste and aggregate in concrete, neutralizing alkaline compounds, resulting in a decrease of $\mathrm{pH}$ to less than nine, thus widely destroying the passive protection layer and causing corrosion [4, 13-16] (Fig. 1). 


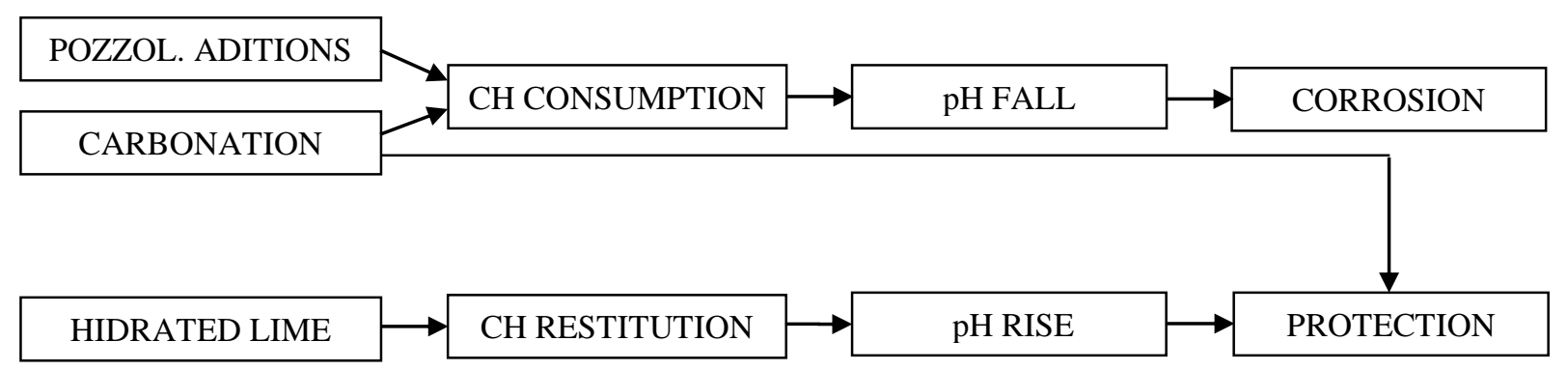

Fig. 1 - Carbonation in concrete containing high volumes of pozzolan addition

The primary alkaline compounds presented in the hydrated paste susceptible to react with carbon dioxide are the hydroxides of potassium, sodium and calcium $(\mathrm{CH})$, being the last one the most important (Eq. 1). Therefore, this pathology is more susceptible in urban and industrial areas or places with high concentrations of carbon dioxide [17]. The main reaction of concrete carbonation can be expressed by Eq. 1, concerning calcium hydroxide $(\mathrm{CH})$ from cement hydration, environment carbon dioxide $(\overline{\mathrm{C}})$ and resulting calcium carbonate $(\mathrm{C} \overline{\mathrm{C}})$, described in their abbreviated forms.

$$
\mathrm{CH}+\overline{\mathrm{C}} \rightarrow \mathrm{C} \overline{\mathrm{C}}
$$

However, the susceptibility to attack by external agents is also related to the quality of the concrete [18] and the concrete of the modern era may be more vulnerable than traditional one. The composition of the concrete has been suffering many technological advances, mainly since the first half of the twentieth century. One of the most important issues was its ability to incorporate mineral additions such as industrial by-products as cement replacement [19]. The production growing of certain mineral additions like fly ash, creates a problem of processing, storage and control of the environment, which call for more than a decade, finding an effective solution for their use [20]. Once concrete is the second most consumed material by man, exceeded only by water $[19,21,22]$, it is, naturally, an attractive vehicle to incorporate high volumes of industrial by-products with technical, economic and environmental advantages [13, 19, 22-24], being a paradigm of sustainable development of the cement and concrete industry [25]. Nowadays, conventional concrete can be made with $20-40 \%$ of additions. Being even possible in very specific situations reach to $70 \%$ [26]. However, when using high volumes of pozzolanic additions as cement replacement, the phenomenon of carbonation is aggravated [27], and can jeopardize the advantages of using high volumes of mineral additions.

In the cement hydration, the first two hydrate compounds are tricalcium silicate (alite) and dicalcium silicate (belite) (Eq. 2 and 3): these compounds react with water to form calcium silicate hydrates $(\mathrm{C}-\mathrm{S}-\mathrm{H})$ and portlandite $(\mathrm{CH})$. The mechanical strength of the concrete is mainly due to the $\mathrm{C}-\mathrm{S}-\mathrm{H}$. Derivatives of alite are responsible for early age strengths, and derivatives of belite for long term resistances [28]. $\mathrm{CH}$ represents about 20 to $25 \%$ of the volume of solids of the hydrated cement paste, does not participate in strength, has a negative influence on the chemical resistance attack [29], although conferring the necessary concrete alkalinity [21, 30]. In the presence of pozzolanic additions the consumption of $\mathrm{CH}$ in its pozzolanic reaction (Eq. 4) cause a decrease on the alkalinity of concrete. Thus, the susceptibility to carbonation increases [11] (Fig. 1) which in turn accelerates $\mathrm{CH}$ consumption, further worsening the process.

$$
\begin{aligned}
& 2 \mathrm{C}_{3} \mathrm{~S}+6 \mathrm{H} \stackrel{\text { quick }}{\longrightarrow} \mathrm{C}_{3} \mathrm{~S}_{2} \mathrm{H}_{3}+3 \mathrm{CH}+120 \mathrm{cal} / \mathrm{g} \\
& 2 \mathrm{C}_{2} \mathrm{~S}+4 \mathrm{H} \stackrel{\text { slow }}{\longrightarrow} \mathrm{C}_{3} \mathrm{~S}_{2} \mathrm{H}_{3}+\mathrm{CH}+60 \mathrm{cal} / \mathrm{g}
\end{aligned}
$$




$$
x \mathrm{~S}+y \mathrm{CH}+z \mathrm{H} \stackrel{\text { slow }}{\longrightarrow} \mathrm{CSH}_{\text {aditional }}
$$

In this paper one proposes to add artificially the alkalinity which will be consumed by fly ash and by carbonation, incorporating commercial available hydrated lime $(\mathrm{CH})$ in the initial composition. This technique appears to provide two advantages: more reagent for the production of pozzolanic reaction with additional silicates (increased strength and durability) and also higher alkalinity to maintain the passivation layer of steel rebars and provide additional protection against carbonation attack (Fig. 1).

\section{Experimental program}

The experimental program has focused on the study of the mortar compositions presented in Table 1. The adopted reference mixture mix-design was determined in order to be equivalent to the mortar (particles less than $5 \mathrm{~mm}$ ) contained in a self-compacting high performance concrete, made with 500 $\mathrm{kg} / \mathrm{m}^{3}$ of binder, $731 \mathrm{~kg} / \mathrm{m}^{3}$ of aggregate and water-binder ratio (W/B) of 0.25 [31].

For each concrete mixture three mortar mixes were performed with three different W/B and with $1.7 \%$ of superplasticizer (SP) (of the mass of the binder). The total mass of the binder (B) refers to the sum of the masses of the cement (C), fly ash (FA) and metakaolin (MTK). For mix-design purposes, hydrated lime (HL) was tacked into account as an aggregate, along with the sand (S).

After mixing, 40x40x160 $\mathrm{mm}^{3}$ specimens were prepared for testing the accelerated carbonation of all compositions. After mixing and prior to casting workability was evaluated through flow table test [32]. The samples were kept in saturated lime water for curing during 38 days [33]. Subsequently, in the greenhouse, the specimens were subjected to an environment at $40{ }^{\circ} \mathrm{C}$ temperature for two days. Later, two opposite sides and the tops of the two specimens were sealed with paraffin, in order to put them in the climate carbonation chamber with $4 \pm 0.5 \% \mathrm{CO}_{2}, 55 \pm 5 \% \mathrm{RH}$ and $20 \pm 2{ }^{\circ} \mathrm{C}$. The specimens remained in the carbonation chamber for 100 days, thereafter were broken and sprayed with thymolphthalein indicator (Fig. 2 (left)). Prismatic specimens of 40x40x160 mm $\mathrm{mm}^{3}$ were also produced for capillary water absorption test, carried out in accordance with EN 1015-18 [33] and cubic samples with $50 \mathrm{~mm}$ edge for water absorption by immersion test (marked with * in Table 1), carried out according with the specification LNEC E394 [34].

These tests were conducted on carbonated and on non-carbonated samples. So, half of these samples was also subjected to climate carbonation chamber for 100 days and the other half remained immersed in $\mathrm{CH}$ saturated water. Samples for capillary water absorption test were prepared for climate chamber covering with paraffin all sides except the fracture zone, the one that will be in contact with $\mathrm{CO}_{2}$ (Fig. 2 (right)).

Fig. 2 - Specimens sealing with paraffin. Evaluation of carbonation (left) and capillarity (right)

The cement used was a CEM I 42.5R one (Outão, Secil), the aggregate was a commercial available river rolled sand $0 / 4 \mathrm{~mm}$, and next-generation superplasticizer based on modified polycarboxylic ether chain was also used. Considering the importance of characterization of fly ash, a trial of X-ray diffraction (XRD) with a Bruker D8 Advance (Fig. 4) and X-ray fluorescence spectroscopy (XRF) was carried out with a ray equipment Philips X 'Unique II, in order to identify and quantify the reactive phase by Rietveld method. An electronic scanning microscope Hitachi SU1510 (SEM) was also used to evaluate the quality of fly ash, verifying that they are mainly composed by cenospheres particles, some of them (in a small percentage) trapped in carbon clusters (Fig. 3). In order to characterize the potential of $\mathrm{CH}$ contained in the hydrated lime and the amount of calcium carbonate present, simultaneous thermal analysis (STA, Netzsch 402 EP, heating rate of $10{ }^{\circ} \mathrm{C} / \mathrm{min}$ ) was adopted (Fig. 5), and simultaneously with the help of XRD analysis to determine the calcium carbonate crystallization process. The material characteristics are described in Table 2. 
Table 1 - Tested compositions

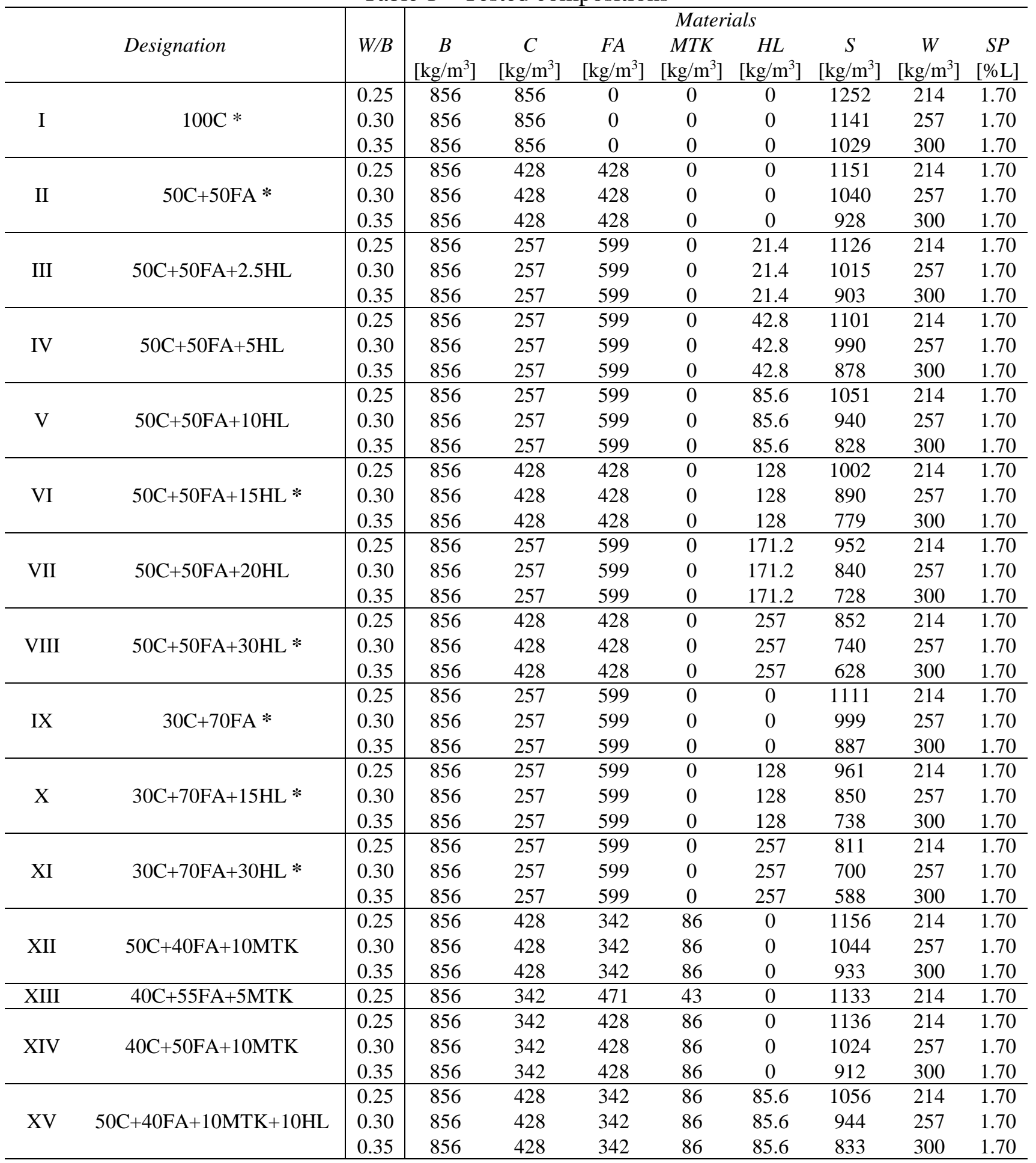

Fig. 3 - SEM fly ash images

Fig. 4 - XRD fly ash spectrum

Fig. 5 - STA hydrated lime results 
Table 2 - Materials characteristics

\begin{tabular}{|c|c|c|c|c|c|c|}
\hline & $C$ & & & & $H L$ & $M T K$ \\
\hline Chemical properties [\%] & [35] & $X R F$ & $M E V$ & $X R D$ & $S T A / X R D[36]$ & {$[37,38]$} \\
\hline $\mathrm{SiO}_{2}$ & 18.27 & 49.12 & 56.83 & 28.7 vitreous* & $<0.4[36]$ & 47.0 \\
\hline $\mathrm{Al}_{2} \mathrm{O}_{3}$ & 4.75 & 27.30 & 28.59 & 22.1 vitreous* & $<0.5[36]$ & 37.1 \\
\hline $\mathrm{Fe}_{2} \mathrm{O}_{3}$ & 3.23 & 8.19 & 6.86 & 4.8 vitreous* & $<0.08[36]$ & 1.3 \\
\hline $\mathrm{CaO}$ & 63.94 & 2.36 & 1.80 & & & 0.1 \\
\hline $\mathrm{CaO}$ free & 1.39 & & & & & \\
\hline $\mathrm{MgO}$ & 1.31 & 1.42 & & & $<0.85[36]$ & 0.15 \\
\hline $\mathrm{SO}_{3}$ & 3.05 & 1.30 & & & & \\
\hline $\mathrm{K}_{2} \mathrm{O}$ & 0.57 & 3.34 & 1.97 & & & 2 \\
\hline $\mathrm{Na}_{2} \mathrm{O}$ & & 0.99 & 1.78 & & & 0.2 \\
\hline $\mathrm{TiO}_{2}$ & & 2.32 & & & & 0.3 \\
\hline $\mathrm{Cl}^{-}$ & 0.09 & & & & & \\
\hline Other & & & & 15.4 vitreous* & & \\
\hline Carbon & & & 3.65 & & & \\
\hline Loss on ignition & 2.72 & 3.97 & & & & 12.75 \\
\hline Insoluble residue & 0.74 & & & & & \\
\hline \multicolumn{7}{|l|}{ Physical properties } \\
\hline Specific gravity $\left[\mathrm{kg} / \mathrm{m}^{3}\right]$ & 3100 & \multirow{2}{*}{\multicolumn{3}{|c|}{2420}} & $<0.08[36]$ & 2590 \\
\hline Blaine $\left[\mathrm{cm}^{2} / \mathrm{g}\right]$ & 4315 & & & & & \\
\hline \multicolumn{7}{|l|}{ Mineralogical properties [\%] } \\
\hline Quartz & & & & 18.41 & & \\
\hline Mullite & & & & 7.18 & & \\
\hline Hematite & & & & 3.41 & & \\
\hline Total crystalline phase * & & & & 29.00 & & \\
\hline Total glassy phase & & & & 71.00 & & \\
\hline Portlandite & & & & & 75.8 & \\
\hline Calcite & & & & & 22.6 & \\
\hline * Rietveld method & & & & & & \\
\hline
\end{tabular}

The analysis of Fig. 4 and Table 2, show that the major crystalline phases of the fly ash are quartz, mullite and hematite. Apart these phases we can see that there is a significant amount of glassy phase which is estimated around $71 \%(28.7+22.1+15.4+4.8)$, with a carbon content of $3.65 \%$, indicating a reasonable reactivity of the used fly ash. Due the fly ash fineness it is also expected some important influence of filler effect [27]. The observation of Fig. 5 for the hydrated lime showed the presence of some free water identified in the initial temperatures (peak A), the decomposition of portlandite between 410 and $620^{\circ} \mathrm{C}$ (peak B) and the decomposition of calcium carbonate between $620{ }^{\circ} \mathrm{C}$ and $965^{\circ} \mathrm{C}$ (peak C).

\section{Analysis of results}

\section{Workability}

The flow test obtained results are presents in Fig. 7. According to this figure analysis, some mixes didn't show adequate workability or present segregation (IX-c) and were therefore rejected. It became apparent that the addition of fly ash increases the workability while the addition of lime decreases it. This workability loss is such that it was impossible to manufacture a mixture of $50 \%$ fly ash with 
$15 \%$ hydrated lime (composition VI-a). This is indicative that higher quantities of hydrated lime addition can improve the workability problems occurrence.

Fig. 6: Flow-test results

\section{Electrical resistivity}

The electrical resistivity was determined and the obtained results are presented in Fig. 7. Each result corresponds to the average value for measurements in 4 major faces of the specimens $40 \times 40 \times 160 \mathrm{~mm} 3$. One resistivity meter at $38 \mathrm{~mm}$ spacing between probes was used. According to the results (Fig. 7), the use of additions increased the electrical resistivity, especially in mixtures containing metakaolin and in the ternary mixtures made with $50 \%$ fly ash and lime in moderate amounts (up to $10 \%$ inclusive). This might be due to the greater compactness of the mixtures in the presence of the additions which may result in a greater difficulty of the aggressive agent to diffuse, thereby increasing its durability when compared with the reference, produced without any addition.

Fig. 7: Electrical resistivity results at 40 days

\section{Carbonation}

The obtained results presented in Fig. 8 shown that the depth of carbonation was higher in mixtures containing mineral additions, especially fly ash. This may result as a consequence of the consumption of $\mathrm{CH}$ in the pozzolanic reaction. Generally, the incorporation of hydrated lime leads to lower carbonation depths. This effect was more pronounced up to moderate amounts (up to $10 \%$ ) of $\mathrm{CH}$ and low W/B ratio. This may be due to the fact that the vitreous silica of the fly ash could not react with all the available lime, so that the surplus of lime even though it contributes to the maintenance of the $\mathrm{pH}$ did not contribute to the production of additional $\mathrm{CHS}$ and consequent densification of the matrix.

The carbonation results shown that the use of metakaolin together with fly ash was not so effective, probably because they consumed even more $\mathrm{CH}$ or because the increased density of the matrix due to the use of metakaolin was not enough to avoid the diffusion of $\mathrm{CO}_{2}$.

Fig. 8: Carbonation depth

\section{Water absorption by immersion and by capillarity}

The water absorption by immersion test results allowed evaluating the open porosity and are presented in Fig. 9. The test of water absorption by capillary action made allowed the possibility to quantify the coefficient of capillary absorption, determined using the of least squares method, considering only the results obtained at 10 and 90 minutes of testing (Fig. 10). This index refers to the ratio between the mass of water absorbed per unit area as a function of square root of time. 
As can be seen, both the open porosity and capillary absorption coefficient increased with the use of additions. The use of additions changes the pores dimension and its quantity and may lead to an increase of the micropores and a decrease of the macropores [11], which may explain the increase in the coefficient of capillary absorption. Furthermore, the presence of a large amount of fines particles, without pozzolanic reactivity, could also increase the coefficient of capillary absorption [39], which is congruent with the apparent low reactivity of the used fly ash. The total porosity tends to increase with the additions, because the main responsibility for the reduction of the voids of the matrix comes from the cement hydration [27]. The hydrated lime and fly ash will probably have more responsibility in the pores refining.

Fig. 9: Water absorption by immersion (open porosity)

Fig. 10: Water absorption by capillarity

In the carbonated specimens (with or without additions) the open porosity was lower, having an inverse pattern in the coefficient of capillary absorption. Since the density of calcium carbonate is higher than the $\mathrm{CH}$, can give an increase in the solid phase, which according Younsi [13] can go from 3 to $19 \%$. On the other hand, if there is no space in the matrix to accommodate this increase, this may lead to microcracking [40], which could explain the increased coefficient of capillary absorption. The increase of micropores also can consistently explain the increase in the capillary coefficient absorption with the carbonation because there are higher pores amount and with smaller radius.

The kinetics of capillary absorption over time is expressed in Fig. 11. For compositions (I, II, VIII, IX and XI) it was characterized by a large difference between the non-carbonated and the carbonated specimens. These last ones showed higher values. One exception was detected for composition with $50 \%$ fly ash and $15 \%$ of lime (VI) whose difference was very slight (Fig. 11). This may be due to a more compact array supplied for the lime, thereby restricting the creation of carbonation products. Knowing that the capillary absorption coefficient can be strongly influenced by fracture zones, especially at the interfacial transition zone [39], the healing process in this zone by carbonation, mainly in the presence of available portlandite, could also explain this result: the increased capillary absorption coefficient due to the decrease of the radius of the pores but, at the same time, there has been an increased formation of additional C-S-H which blocked the capillary network.

Fig. 11: Kinetics of capillary absorption over time

\section{Conclusion}

The incorporation of hydrated lime can be a promising tool with potential to develop strength to carbonation of concrete with high volume of fly ash and therefore assure the production of ecoefficient and durable concrete. Although the chemical composition is similar to the $\mathrm{CH}$ resulting from cement hydration, the "artificial" incorporation of commercially available $\mathrm{CH}$ changes the reaction kinetics, mainly because a large amount of reagents is present from the beginning of the reaction and not throughout its maturity (Eq. 2 to 4). The best results was obtained for lowers amounts of hydrated lime, up to $10 \%$. This small amount may be related to the quality of the fly ash, particularly the amount of its amorphous silica content. Another possible explanation could be given for the best synergy achieved because large amounts of $\mathrm{CH}$ allow the $\mathrm{pH}$ increase, maintain active the passivation layer of steel bars reinforcement and provide corrosion protection. On the other hand, if the concentration of $\mathrm{CH}$ added in the beginning of the mixing is too high, this excessive presence can be harmful, since the portlandite not converted into additional C-S-H will be subject to deleterious effects [29]. Future work should develop a methodology that allows associating the amount and type of fly ash with an optimal amount of hydrated lime to add at the beginning of the mixture process. Further studies should focus on concrete mixtures of high performance (W/B $\leq 0.40$ ), with a high volume of additions, but with a maximum amount of binder up to $350 \mathrm{~kg} / \mathrm{m}^{3}$. 


\section{Acknowledgements}

The authors wish to acknowledge the team of the Laboratory of Building Materials of University of Minho and the Unit for Research and Development Materials of ESTG from Polytechnic Institute of Viana do Castelo in this research collaboration. The authors also wish to thank Secil SA, BASF SA and Mota Engil by its kindly supply of cement, superplasticizer and fly ashes, respectively.

SEM and XRD facilities were funded by FEDER Funds through QREN - Aviso SAIECTIEC/2/2010, Operação NORTE-07-0162-FEDER-000050.

\section{References}

[1] P. Helene, Introdução, in: P. Helene (Ed.), Manual repair, protection and strengthening of concrete structures (in Portuguese), Degussa Construction Chemical Brasil, São Paulo, 2008.

[2] M.I. Khan and C.J. Lynsdale, Strength, permeability, and carbonation of high-performance concrete, Cement and Concrete Research. 32 (2002) 123-131.

[3] O. Rincón, et al., Manual inspection, assessment and diagnosis of corrosion in reinforced concrete structures (in Spanish), CYTED (Programa Iberoamericano de Ciência y Tecnologia para el Desarrollo), Habana, 1997.

[4] J.P. Broomfield, Corrosion of steel in concrete: understanding investigation and repair, E \& FN Spon, London, 1997.

[5] G. Polito, Corrosion in reinforced concrete structures: causes, mechanisms, prevention, and recovery (in Portuguese), Degree thesis, 2006.

[6] H.J. Lee, et al., A study for carbonation degree on Concrete using a phenolphthalein indicator and fourier-transform infrared spectroscopy, International Journal of Civil and Environmental Engineering. 34 (2012) 184-190.

[7] F.P. Torgal, et al., An overview on concrete carbonation in the context of eco-efficient construction: evaluation, use of SCMs and/or RAC, Construction and Building Materials. 36 (2012) 141-150.

[8] T. Gonen and S. Yazicioglu, The influence of compaction pores on sorptivity and carbonation of concrete, Construction and Building Materials. 21 (2007) 1040-1045.

[9] M. Thiery, Modélisation de la carbonatation atmosphérique des Matériaux cimentaires: prize en compte des effets et des cinétiques microstructurales et hydriques, civil engineering modifications (in French), PhD thesis, 2005.

[10] I. Monteiro, Modelling the evolution of carbonation in reinforced concrete elements (in Portuguese), Master thesis, 2010.

[11] A. Hoppe, Carbonation in concrete with gray cazca rice without crushing (in Portuguese), Master thesis, 2008.

[12] W. Casore, Study of carbonation of concrete overlay prototypes layer with high contents of mineral additions and hydrated lime (in Portuguse), Master thesis, 2008.

[13] A. Younsi, Carbonation of concrete with high rates of substitution of cement with mineral additions (in French), Engenharia civil. PhD thesis ,2011.

[14] G. Villain, M. Thiery, and G. Platret, Measurement methods of carbonation profiles in concrete: thermogravimetry, chemical analysis and gammadensimetry, Cement and Concrete Research. 37 (2007) 1182-1192.

[15] J. Khunthongkeaw, S. Tangtermsirikul, and T. Leelawat, A study on carbonation depth prediction for fly ash concrete, Construction and Building Materials. 20 (2006) 744-753.

[16] E.P. Figueiredo, et al., Guideline for the diagnosis, in: P. Helene (Ed.), Manual repair, protection and strengthening of concrete structures (in portuguses), Degussa Construction Chemical Brasil, São Paulo, 2008.

[17] V.G. Papadakis, Effect of supplementary cementing materials on concrete resistance against carbonation and chloride ingress, Cement and Concrete Research. 30 (2000) 291-299.

[18] IPQ, NP EN 206-1:2007, Concrete. Part 1: Specification, performance, production and conformity (in Portuguses), 2007. 
[19] G.C. Isaia and A.L.G. Gastaldini, Concrete sustainability with very high amount of fly ash and slag, IBRACON strutures and materials journal. 2 (2009) 244-253.

[20] K.R. Hwang, T. Noguchi, and F. Tomosawa, Effects of fine aggregate replacement on the rheology, compressive strength and carbonation properties of fly ash and mortar, 6th International conference on the use of fly ash, silica fume, slag, and natural pozzolans in concrete. (1998) 401-410.

[21] B.B. Sabir, S. Wild, and J. Bai, Metakaolin and calcined clays as pozzolans for concrete: a review, Cement and Concrete Composites. 23 (2001) 441-454.

[22] G.C. Isaia and A.L.G. Gastaldini, Environmental and economic perspectives of concrete with high content of mineral additions: a case study (in Portuguese), Ambiente Construído. 4 (2004) 19-30.

[23] M. Dal Ri, Effects of the addition of hydrated lime in concrete with high levels of mineral admixture on chloride penetration and aqueous pores of the concrete, $\mathrm{PhD}$ thesis, 2002.

[24] A. Younsi, et al., Performance-based design and carbonation of concrete with high fly ash content, Cement and Concrete Composites. 33 (2011) 993-1000.

[25] P.K. Mehta, Role of pozzolanic and cementitious material in sustainable development of the concrete industry, 6th International conference on the use of fly ash, silica fume, slag, and natural pozzolans in concrete. (1998) 1-25.

[26] P.K. Mehta and P. Monteiro, oncrete: microstructure, properties and materials (in Portuguese), 3. ${ }^{a}$ ed, IBRACON (Instituto Brasileiro do Concreto), São Paulo, 2008.

[27] J. Filho, Cement systems, steering and hydrated lime ash: hydration mechanism, microstructure and carbonation of concrete (in Portugusese), $\mathrm{PhD}$ thesis, 2008.

[28] A. Neville, Properties of concrete, 3rd ed, Longman Scientific \& Technical, Singapore, 1994.

[29] M. Anjos, et al., Evaluation of hydration of cement pastes containing high levels of mineral additions (in Portuguese) (2013).

[30] A. Coutinho, Manufacture and properties of concrete (in Portuguese), 4. ${ }^{\mathrm{a}}$ ed, LNEC (Laboratório Nacional de Engenharia Civil), Lisbon, 2006.

[31] A. Camões, Use of fly ash in concrete, International RILEM Workshop on Performance Based Evaluation and Indicator for Concrete Durability, (1996) 311-318.

[32] Cen, EN 1015-3: 2004, Methods of test for mortar for masonry - part 3: determination of consistence of fresh mortar (by flow table). 2004.

[33] Cen, EN 1015-18:2002, Methods of test for mortar for masonry - Part 18: Determination of water absorption coefficient due to capillary action of hardened mortar (english version), 2002.

[34] LNEC, E 394:1993, Determination of water absorption by immersion (in Portuguese), 1993.

[35] SECIL, Cimento Portland EN 197-1 CEM I 42.5: Self monitoring results (in Portuguese), 2013.

[36] CALCIDRATA, Sheet Product Specification: hydrated lime, Class 1, Grade A, Type 1 according to EN 12518 (in Portuguese), 2010.

[37] A.T. Pinto, Binder systems obtained by alkaline activation of metakaolin, $\mathrm{PhD}$ thesis, 2004.

[38] R. Reis, Eco-efficient concrete with fly ash and metakaolin, Master thesis, 2009.

[39] A. Coutinho and A. Gonçalves, Manufacture and properties of concrete (in Portuguese), 2. ${ }^{\mathrm{a}}$ ed, LNEC (Laboratório Nacional de Engenharia Civil), Lisbon, 1994.

[40] A. Abreu, Study of corrosion of reinforcement induced by carbonation in concrete with fly ash (in Portuguese), $\mathrm{PhD}$ thesis, 2004. 